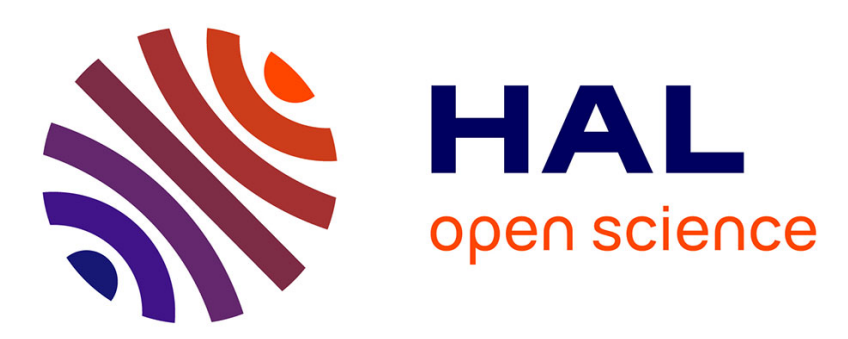

\title{
Volatile components as chemical markers of the botanical origin of Corsican honeys
}

Yin Yang, Marie-José Battesti, Jean Costa, Nathalie Dupuy, Julien Paolini

\section{To cite this version:}

Yin Yang, Marie-José Battesti, Jean Costa, Nathalie Dupuy, Julien Paolini. Volatile components as chemical markers of the botanical origin of Corsican honeys. Flavour and Fragrance Journal, 2018, 33 (1), pp.52 - 62. 10.1002/ffj.3414. hal-01730703

\section{HAL Id: hal-01730703 https://hal.science/hal-01730703}

Submitted on 12 Apr 2018

HAL is a multi-disciplinary open access archive for the deposit and dissemination of scientific research documents, whether they are published or not. The documents may come from teaching and research institutions in France or abroad, or from public or private research centers.
L'archive ouverte pluridisciplinaire HAL, est destinée au dépôt et à la diffusion de documents scientifiques de niveau recherche, publiés ou non, émanant des établissements d'enseignement et de recherche français ou étrangers, des laboratoires publics ou privés. 


\title{
Volatile components as chemical markers of the botanical origin of Corsican honeys
}

\author{
Yin Yang ${ }^{1}$ | Marie-José Battesti ${ }^{1}$ | Jean Costa $^{1}$ | Nathalie Dupuy ${ }^{2}$ | Julien Paolini ${ }^{1}$
}

${ }^{1}$ Université de Corse, UMR CNRS 6134, Laboratoire Chimie des Produits Naturels, Campus Grimaldi BP 52, 20250 Corte, France

${ }^{2}$ Aix-Marseille Université, IMBE UMR 7263,

Avenue Escadrille Normandie Niemen, 13397

Marseille, France

Correspondence

Julien Paolini, Université de Corse, UMR CNRS 6134, Laboratoire Chimie des Produits Naturels, Campus Grimaldi, BP 52, 20250

Corte, France.

Email: paolini@univ-corse.fr

\begin{abstract}
In accordance with the national Appellation d'Origine Contrôlée and the European Protected Designation of Origin labels, Corsican honeys can be classified into six ranges (spring, spring maquis, honeydew maquis, chestnut grove, summer maquis and autumn maquis). Toward proposing a new and faster method for performing honey quality assessments, an headspace-solid phase microextraction (HS-SPME)/Gas Chromatography (GC)/GC-Mass Spectrometry (MS) method with multivariate data analysis - principal component analysis (PCA), cluster analysis (CA), partial lest square (PLS) - was developed using 269 Corsican samples, for which the volatile compositions were established a priori. Corsican honeydew and blossom honey could be differentiated by the richness of 3-furaldehyde in the category of "honeydew maquis". This approach also allowed identification of chemical markers of the botanical origins of blossom honeys, including 2-aminoacetophenone, $p$-anisaldehyde, 4-n-propylanisole, isophorone, and isomers of lilac aldehyde. Therefore, characterization of the volatile fraction of Corsican honeys combined with chemometric analysis may be useful for detecting the nectar contribution of plant species in honeys with complex nectariferous origins.
\end{abstract}

\section{KEYWORDS}

Corsican honey, HS-SPME/GC/GC-MS, PCA, PDO, PLS

\section{1 | INTRODUCTION}

With its rich melliferous plant species and endemic black honeybee, Corsica possesses a suitable natural environment for the development of a beekeeping sector. In accordance with the national Appellation d'Origine Contrôlée (AOC) and the European Protected Designation of Origin (PDO) labels, ${ }^{1}$ Corsican honeys can be classified into six ranges ("spring", "spring maquis", "honeydew maquis", "chestnut grove", "summer maquis" and "autumn maquis") depending on apiary location (main plants visited by honeybee), harvest period, melissopalynological data, and organoleptic properties of the honeys. ${ }^{2}$ In addition, the "honeydew maquis" has been divided into two categories according to the honeydew origin of its raw material; typical Mediterranean honeydew is generally produced from rockrose (Cistus sp.) in littoral areas, oak (Quercus sp.), and/or chestnut (Castanea sativa) forests, while Metcalfa honeydew was obtained after the appearance of the insect
Metcalfa pruinosa in Corsica in $1995 .^{3}$ The typical Mediterranean and Metcalfa honeydews are distinct in terms of color (dark amber and very dark, respectively) and viscosity (weak and high, respectively). Currently, production of the Corsican honeys in the "honeydew maquis" range are essentially obtained from $M$. pruinosa.

Quality assessment of the two official designations PDO and AOC "Miel de Corse - Mele di Corsica" has been based on melissopalynological data considering the entire pollen spectrum via statistical analysis. ${ }^{4-6}$ This method is associated with physico-chemical parameters (i.e., water content, coloration, and conductibility) that are still considered an official method for honey certification. ${ }^{1}$ However, researchers have recently begun to identify new criteria for determining the botanical origin of honeys. Their work has frequently focused on the identification of chemical biomarkers such as amino acids, sugar, phenolic and/or volatile compounds. ${ }^{7-9}$ These methods have been considered complementary because their procedures are usually not standardized and their analytic parameters are often adapted according to the botanical honey sample origin, targeted chemical compounds, and/or apparatus. However, these methods also offer new opportunities for defining the interactions between 
the organoleptic properties of honeys and the melliferous plant resources. In terms of authentication, the development of interdisciplinary approaches (palynological, sensorial, and chemical analysis) is preferable for characterizing botanical and geographical origins.

Work on the volatile composition of honeys started in the early 1960 s and to date, approximately 600 compounds belonging to various chemical families have been identified according to their botanical and/or geographical origins. ${ }^{9,10}$ The extraction of volatile components from honeys has usually been performed using headspace-solid phase microextraction (HS-SPME), simultaneous steam distillation-solvent extraction, hydrodistillation or ultrasound-assisted extraction. ${ }^{9-11}$ Most studies have focused on monofloral honeys, and constituents such as methyl anthranilate, methyl syringate and isophorone have been reported as chemical markers of the botanical origins of citrus, asphodel and strawberry tree honeys, respectively. ${ }^{11-13}$ To our knowledge, no study to date has focused on the volatile composition of Metcalfa honeydew honeys, but various chemical markers of others honeydew honeys have been previously described; these have included oaklactone (oak honeydew), ${ }^{14}$ acetic acid, ${ }^{15}$ 2,3-butanediol, ${ }^{16}$ and borneo ${ }^{17}$ (botanical raw material origin not specified).

The volatile fraction of Corsican honeys has been studied toward discriminating geographical origins (Corsican and non-Corsican honeys) ${ }^{18,19}$ Moreover, the relationships between chemical variability, pollen diversity, and physico-chemical parameters of each range of Corsican honeys (except "honeydew maquis" honey) have been established using an interdisciplinary approach. ${ }^{20-24}$ Based on these previous studies, the aim of the present work was to provide an overview of the volatile composition of Corsican honeys, including blossom and honeydew honeys (in all six PDO ranges), as well as blend honeys with mixed melliferous origins (presence of nectar and honeydew contributions). The objective of this research was to purpose a new and faster approach for honey quality assessment utilizing an HS-SPME/ GC/GC-MS-based method with multivariate data analysis (PCA, CA, PLS) to certify the botanical origin of 269 Corsican samples, for which the volatile compositions were established $a$ priori.

\section{2 | EXPERIMENTAL}

\section{1 | Honey sampling}

269 honeys samples were selected from the reference bank of the University of Corsica. These samples included the six ranges of Corsican honeys commercialized under AOC and PDO appellations: 50 "chestnut grove" (CH01-CH50), 45 "spring maquis" (MP01-MP45), 41 "spring" (PR01-PR41), 29 "summer maquis" (ME01-ME29), 30 "autumn maquis" (MA01-MA30), 48 "honeydew maquis" (MM01MM48) and 26 blend honeys (MM49-MM74). Taking into account of the regional plant diversity and bioclimatic annual variations, the honey samples were provided from 74 beekeepers and various years of production between 2003 and 2013. After the harvest, these honeys were packaged directly in a sealed pot and stored at $14^{\circ} \mathrm{C}$, which was the optimal condition for avoid the degradation of samples. ${ }^{25}$ Before analysis, the selected honeys were examined by sensory analysis to ensure the conservation process.

\section{2 | Melissopalynological and physico-chemical analysis}

The melissopalynological and physico-chemical analysis of the 269 Corsican honeys was carried out using the methodology previously reported. ${ }^{20}$ These results have enabled to establish the classification of samples under the varietal ranges of AOC/PDO appellation and the certification of geographical and botanical origins. The pollen spectrum (relative frequency of taxa and pollen density) and the physicochemical parameters (coloration and electrical conductivity) of the blossom honey samples were also described in previous studies. ${ }^{20-24}$ Pollen analysis allowed identification of 131 plant taxa in Corsican honeys. Their geographical origin was certified according to the Decree $n^{\circ} 2013-1057^{1}$ of Corsican AOC/PDO honey including the chorological and ecological analysis of pollen directory, the diversity of biogeographical origin of taxa, the presence of marker species (endemic and/or subendemic) and the absence of characteristic taxa of other Euro-Mediterranean honeys. ${ }^{1,2,5}$

\section{3 | Volatile composition analysis}

The volatile composition of samples was established using HS-SPME followed by GC-FID and GC-MS analyses. A divinylbenzene/ carboxen/polydimethylsiloxane (DVB/CAR/PDMS, $30 \mu \mathrm{m}$ ) SPME fiber was used to extract the volatile components from honey. Optimization of the SPME parameters was carried out using the methodology reported previously. ${ }^{20-24}$

GC-FID and GC-MS analyses were performed using a PerkinElmer (Waltham, MA, USA) AutoSystem XL GC apparatus equipped with a FID system or coupled to a PerkinElmer TurboMass detector (quadrupole). A fused-silica capillary column (30 $\mathrm{m} \times 0.25 \mathrm{~mm}$, film thickness 1 $\mu \mathrm{m})$ coated with Rtx-1 (PDMS) was used. The oven temperature was programmed from 60 to $230^{\circ} \mathrm{C}$ at $2^{\circ} \mathrm{C} / \mathrm{min}$ and then held isothermally at $230^{\circ} \mathrm{C}$ for $35 \mathrm{~min}$. Other analytical parameters were described in our previous works as SPME inlet liner: $0.75 \mathrm{~mm}$ i.d. Supelco; injector temperature: $280^{\circ} \mathrm{C}$; carrier gas: hydrogen and/or helium $1 \mathrm{ml} / \mathrm{min}$; detector FID temperature: $280^{\circ} \mathrm{C}$; MS source temperature: $150^{\circ} \mathrm{C}$ (ionization energy: $70 \mathrm{eV}$ ). Identification of the components was based on the comparison of their mass spectra and retention indices (relative to the retention times of a series of $n$-alkanes $C_{5}-C 30$ [alkane standard mixture, Sigma-Aldrich]) with linear interpolation with those of authentic compounds, data of the laboratory's library or commercial libraries. ${ }^{26}$ The relative concentrations of components were calculated from the GC peak areas obtain by GC-FID without using correction factors. The main goal of the study was to provide a differentiation of the honey varieties using composition of HS-SPME volatile fractions. The relative percentages obtained by GC-FID are used only for comparative purposes to get patterns of volatile profiles, and do not reflect the real amounts of compounds in honey samples, since these values are obtained by SPME without any internal standardization.

Optimization of the SPME parameters was carried out with seven honey samples (two for "spring" honey rang and one for each other category) and was based on the sum of the total peak areas measured using a gas chromatography-flame ionization detection (GC-FID) system. These samples were subjected to HS-SPME in a $20 \mathrm{ml}$ vial. The 
honey concentration in distilled water was optimized after six different experiments $(0.5 \mathrm{~g} / \mathrm{ml}, 1 \mathrm{~g} / \mathrm{ml}$, and $2 \mathrm{~g} / \mathrm{ml})$ with $\mathrm{Na}_{2} \mathrm{SO}_{4}$ addition $(1 \mathrm{~g}$ and $2 \mathrm{~g})$. For each sample, the temperature $\left(25^{\circ} \mathrm{C}, 50^{\circ} \mathrm{C}\right.$ and $\left.70^{\circ} \mathrm{C}\right)$, the equilibration time $(30,60$ and $90 \mathrm{~min})$ and the extraction time (15, 30 and $45 \mathrm{~min}$ ) was also optimized in various experiments. For all honey samples, the extraction parameters were chosen as follows: $4 \mathrm{~g}$ of honey sample with $4 \mathrm{ml}$ of water and $2 \mathrm{~g}$ of $\mathrm{Na}_{2} \mathrm{SO}_{4}$ at a temperature between $70^{\circ} \mathrm{C}$ to $90^{\circ} \mathrm{C}$, an equilibrium time of $90 \mathrm{~min}$, and an extraction time between $30 \mathrm{~min}$ to $45 \mathrm{~min}$.

\section{4 | Chemometric analysis}

\subsubsection{Unsupervised pattern recognition}

Principal Component Analysis (PCA) is unsupervised pattern recognition and it is often the first step of exploratory data analysis to detect groups in the measured data. PCA models the directions of maximum variations in a data set by projecting as a swarm of points in a space defined by principal components (PCs). PCs describe, in decreasing order, the higher variations among the objects, and because they are calculated to be orthogonal to another one, each PC can be interpreted independently. That permits an overview of the data structure by revealing relationships between the objects as well as the detection of deviating objects. To find these sources of variations, the original data matrix is decomposed into the object space, the variable space, and the error matrix. The error matrix represents the variations not explained by the previously extracted PCs and is dependent on the problem definition. ${ }^{27}$ The PCA algorithm is used with mean centered data.

\subsection{2 | Partial lest square regression}

This technique can be adapted for classification ${ }^{28,29}$ as well as for quantitative analysis. The model was built by the full cross validation method during the calibration developments. The evaluation of the errors in the calibration was carried out by computing the standard error of calibration (SEC) after comparing the real concentration with the computed one for each component. The formula for the standard error of calibration is:

$$
S E C=\sqrt{\left(\frac{\sum_{i=1}^{N}\left(C_{i}-C_{i}^{\prime}\right)^{2}}{N-1-p}\right)}
$$

where $C_{i}^{\prime}$ is the known value, $C_{i}$ is the value calculated by the calibration equation, $\mathrm{N}$ is the number of samples, and $p$ is the number of independent variables in the regression optimized by cross-validation.

The standard error of prediction (SEP) gives an estimation of the prediction performance during the step of validation of the calibration equation:

$$
\mathrm{SEP}=\sqrt{\left(\frac{\sum_{i=1}^{M}\left(C_{i}-C_{i}^{\prime}\right)^{2}}{M}\right)}
$$

where $M$ is the number of samples in the prediction set.
PLS-discriminant analysis (DA) method: PLS-DA is carried out using an exclusive binary coding scheme with one bit per class. Therefore, for each sample, the origin may be represented by a multidimensional output vector with 1 at the position corresponding to varietal origin and 0 at the other positions. During the calibration process, the PLS-DA method is trained to compute the "membership values," one for each class; the sample is then assigned to the class showing the highest membership value. ${ }^{30}$ Six models were computed, one for each origin. Two data sets were using the calibration one and the prediction one. The data set were randomized, $50 \%(n=138)$ of the samples were used for the calibration set and $50 \%(n=134)$ were used on the prediction one. The performance of the calibration models was estimated from the percentage of correctly classified samples (\%CC). The \%CC was estimated by the formula:

$$
\% \mathrm{CC}=\mathrm{Nc} /(\mathrm{Nc}+\mathrm{Nic}) \cdot 100
$$

where $N_{c}$ is the number of correctly classified samples and $N_{i c}$ is the number of incorrectly classified samples. ${ }^{31}$

The chemometric applications are performed by the UNSCRAMBLER software version X10.3 from CAMO (Computer Aided Modelling, Trondheim, Norway).

\section{5 | Cluster analysis}

The chemical data was also subjected to cluster analysis (CA) by performing R software (R Foundation-Institute for Statistics and Mathematics, Melbourne, Austria). The CA produced a dendrogram (tree) using Ward's method of hierarchical clustering, which is based on the Euclidean distance between pairs of honey samples.

\section{3 | RESULTS AND DISCUSSION}

\section{1 | Melissopalynological characteristics of Corsican honeys}

Melissopalynological analysis allows identification of the main nectariferous species and/or characteristic plant associations for each blossom honey. The pollen profiles of two honey ranges are distinguished by "over" represented taxa of $C$. sativa (associated essentially with Rubus sp.) and "normal" represented taxa of Erica arborea (combined with other characteristic spring nectariferous species such as Genista sp., Salix sp., Lavandula stoechas, Prunus sp., Viburnum tinus and Crataegus monogyna) for "chestnut grove" (CH01-CH50) and "spring maquis" samples (MP01-MP45), respectively. The pollen spectrum of "autumn maquis" honey (MA01-MA30) exhibited "under" represented taxa of Arbutus unedo, associated with typical autumnal species as Hedera helix, Smilax aspera and Rosmarinus officinalis. The botanical origins of "spring" are more complex with "under" represented taxa in pollen spectrum. Two groups were distinguished from the "spring" range: "spring clementine" honeys (PR01-PR18), which were characterized by the association of cultivated plants, especially Citrus sp., Actinidia sinensis and Prunus sp., and "non-clementine" honeys (PR19-PR41), which were dominated by spontaneous herbaceous or shrub species such as Asphodelus ramosus, Trifolium sp., Echium 
sp., Pistacia lentiscus and Phillyrea sp. The pollen profile of "summer maquis" honeys (ME01-ME29) could be differentiated by the combination of Anthyllis hermanniae, Rubus sp., and endemic high altitude subshrub species such as Thymus herba-barona, Teucrium sp. and Genista sp.

The pollen spectrum of honeydew honey was characterized by the absence of dominant nectariferous taxon and the presence of various microorganisms such as spores, fungi, or microscopic algae, which were referred to as "honeydew indicators". Two types of honeydew honeys were reported: the "Metcalfa honeydew" (MM01-MM43), which was characterized by numerous "honeydew indicators" associated with typical plant genus (Chenopodiaceae/Amaranthaceae, Artemisia sp., Myrtus sp., Eucalyptus sp., Plantago sp. and Asparagus sp.), and "Mediterranean traditional honeydew" (MM44-MM48), which was rich in polleniferous species, especially Cistus sp. from maquis or Quercus sp. from mixed forests and exhibited fewer "honeydew indicators" than "Metcalfa honeydew".

Finally, the pollen spectrum of blend honeys was marked by the presence of "honeydew indicators" and complex nectariferous origins (proportion and taxa association) according to harvest period, such as "chestnut grove" and/or "spring maquis" honey (contributions of $C$. sativa and/or E. arborea, respectively).

\subsection{Volatile composition of Corsican honeys}

HS-SPME, GC, and GC/MS analysis of the volatile fraction of 269 Corsican honeys allowed identification of 102 compounds (Table 1). Among these, only three components were reported in all honey samples, which exhibited a high quantitative variability according to honey range: 3-furaldehyde C10 (0.1-40.1\%), benzaldehyde C21 (0.3-28.0\%), and phenylacetaldehyde C29 (0.1-57.8\%). Although these compounds were detected in 269 honey samples, they could not be considered markers of geographic origin because they are also present in the honeys of other geographic origins in France, Italy, and Germany. ${ }^{32}$

The volatile composition of Corsican honeys was dominated by oxygenated compounds, which accounted for 68.7-96.5\%. In the 195 blossom honeys, the major oxygenated compound class was aromatics (32.9-56.4\%), except for "autumn maquis" honeys, which had isophorone derivatives (42.5\%) as the major class of components. The volatile fraction of "chestnut grove", "spring", and "summer maquis" honeys also exhibited relatively high amounts of linear constituents (30.2\%, $21.8 \%$, and $25.4 \%$, respectively), followed by furan components $(11.9 \%, 15.2 \%$, and $7.7 \%$, respectively), while the "spring maquis" honey possessed only $10.3 \%$ and $9.1 \%$ of the furan and linear compounds. Conversely, the honeydew honeys were rich in furan (29.2\%) and aromatic components (21.3\%), while the blend honeys were characterized by aromatic (47.7\%) and furan constituents (17.9\%). Finally, the volatile composition of Corsican honeys was also characterized by a low concentration of terpenes (0-6.7\%). Therefore, it is noteworthy that the volatile composition of Corsican honeys differed according to their botanical origins.

\subsection{Chemometric analysis of Corsican honeys}

In order to synthesize the chemical variability of Corsican honeys, PCA was performed on volatile data from 269 honeys. As shown in Figure 1 a, the first and second axes (PC1/PC2) explained $27 \%$ of the total variance. The honeydew and blend honeys were differentiated from blossom honeys based on the first Principal Component (PC1). Indeed honeydew and blend honeys exhibited some common chemical characteristics, particularly a higher content of 3-furaldehyde C10 (24.6\% and $13.9 \%$, respectively) than blossom honeys (4.1\%). The second Principal Component (PC2) allowed discrimination of three blossom honey groups: "chestnut grove", "spring" associated with "summer maquis", and "spring maquis" linked to "autumn maquis".

The origins of these samples were also determined using PLS-DA regression. Tables 2 and 3 show these results. The six varieties were discriminated and well predicted with a percent of correct classification between $99-100 \%$, as shown in Table 2. Classification was $100 \%$ correct for the "chestnut grove", "spring maquis", "autumn maquis" and "honeydew" honeys, and 99\% for "summer maquis" and "spring" ranges, with one false sample in each category. The results for prediction of honey origin were excellent. Indeed, of the 131 samples used in the prediction set, only two were not well predicted.

\subsection{Data analysis of blossom honeys}

To improve discrimination between blossom honey ranges, PCA was performed on the honeydew and blend honey samples separately. As shown in Figure 1b, PCA obtained with the first and third axes (PC1/ PC3) explained $36 \%$ of the total variance of volatile fractions from 195 blossom honeys. Thus, six groups were distinguished by the PC1 axis; the "chestnut grove" and "summer maquis" honeys were positively projected. The "chestnut grove" honey was characterized by high content of acetophenone C33 (7.0\%), 2-aminoacetophenone C79 (11.4\%), and some linear acids such as octanoic acid C63 (5.0\%) and nonanoic acid C77 (5.9\%). According to the literature, acetophenone and its derivatives (aminoacetophenones) are considered the chemical markers of chestnut honey. ${ }^{33,34}$ The "summer maquis" honeys were characterized by high amounts of phenylacetaldehyde C29 (33.6\%) and the presence of linear acids such as butanoic acid C7 and 3-methyl butanoic acid C13, which were absent in the other honey samples. Eleven "summer maquis" samples (ME19-ME29) exhibited a significant content of 2-aminoacetophenone $\mathbf{C 7 9}$ (7.2\%), which is considered an indicator of $C$. sativa nectar contribution.

The "spring maquis" and "autumn maquis" were negatively projected. The "spring maquis" honey were characterized by 4propylanisol C75 (14.7\%) and p-anisaldehyde C70 (11.7\%). This latter compound was considered a marker of $E$. arborea honeys because of its absence in honeys of other botanical origins. ${ }^{35}$ The "autumn maquis" honeys were distinguished by their high content of isophorone derivatives (42.5\%) such as isophorone C46 (34.8\%) and 4-oxo-isophorone C47 (3.6\%). These results were in accordance with the volatile composition of $A$. unedo honeys previously described; ${ }^{12,36}$ thus, it could be considered a chemical marker of strawberry tree nectar. The trimethylphenol isomers (31.7\%) such as 2,3,4-trimethylphenol C73 (4.6\%) and 3,4,5-trimethylphenol C83 (27.1\%) were reported only in Corsican A. unedo honey.

The "spring" honeys were differentiated into two subgroups called "spring clementine" and "spring non-clementine" honeys. The "spring clementine" honeys were characterized by lilac aldehyde isomers (C48, 


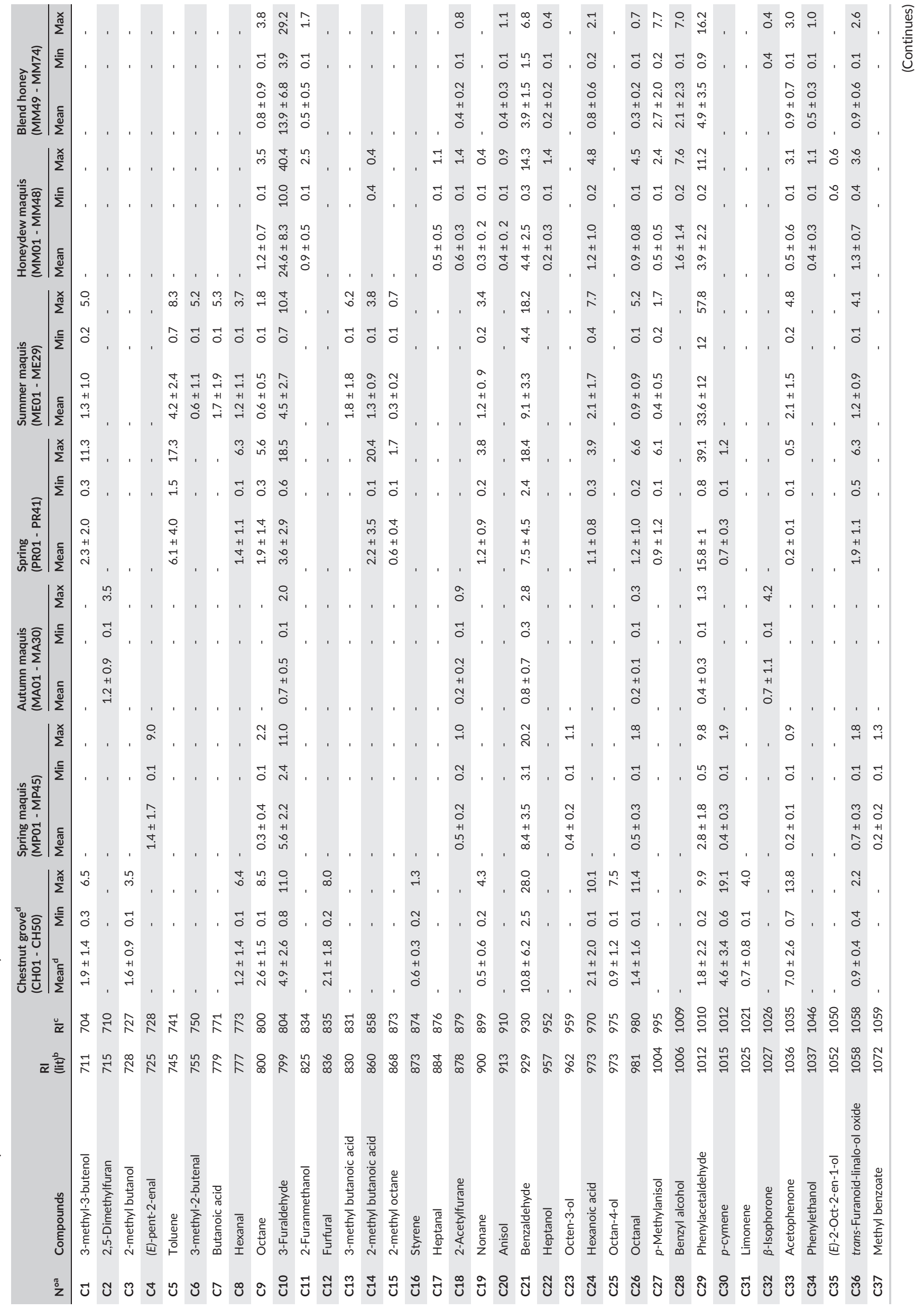




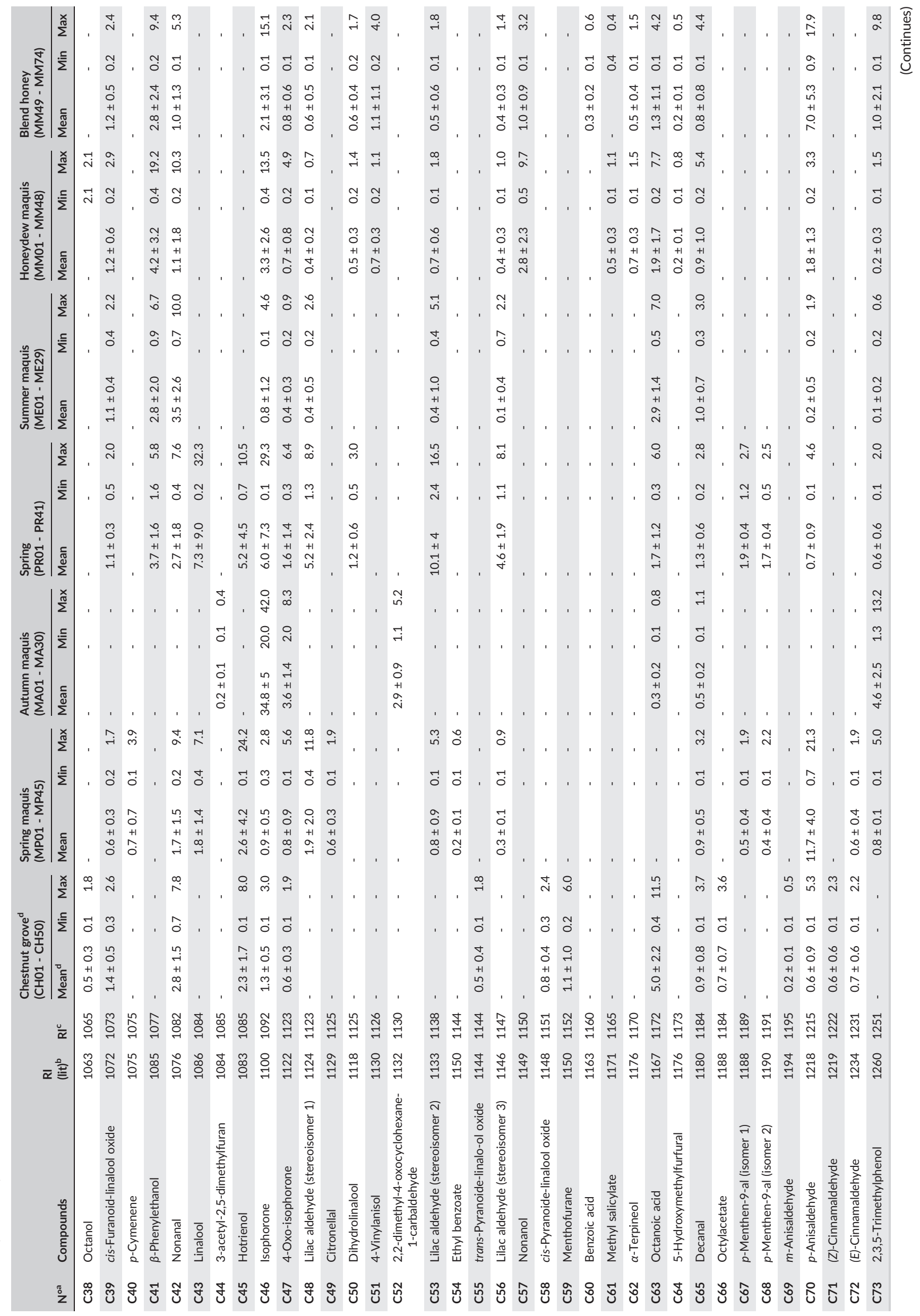




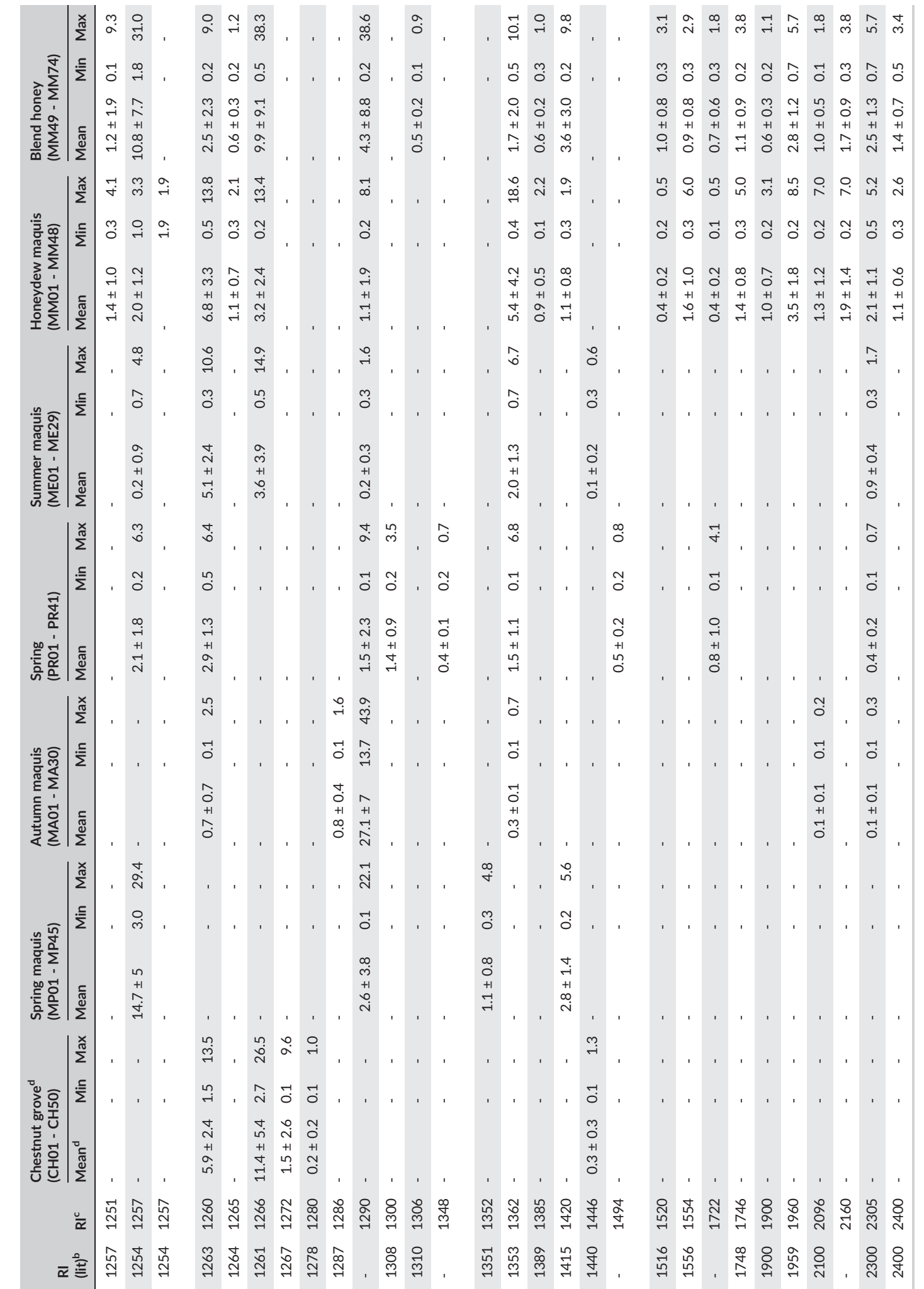

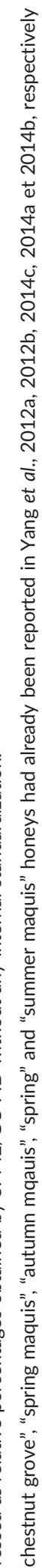

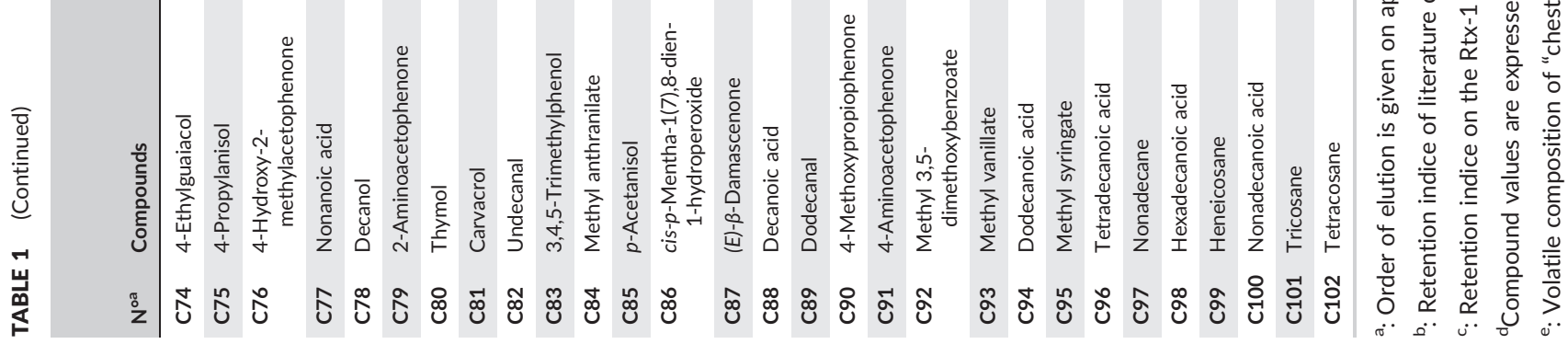




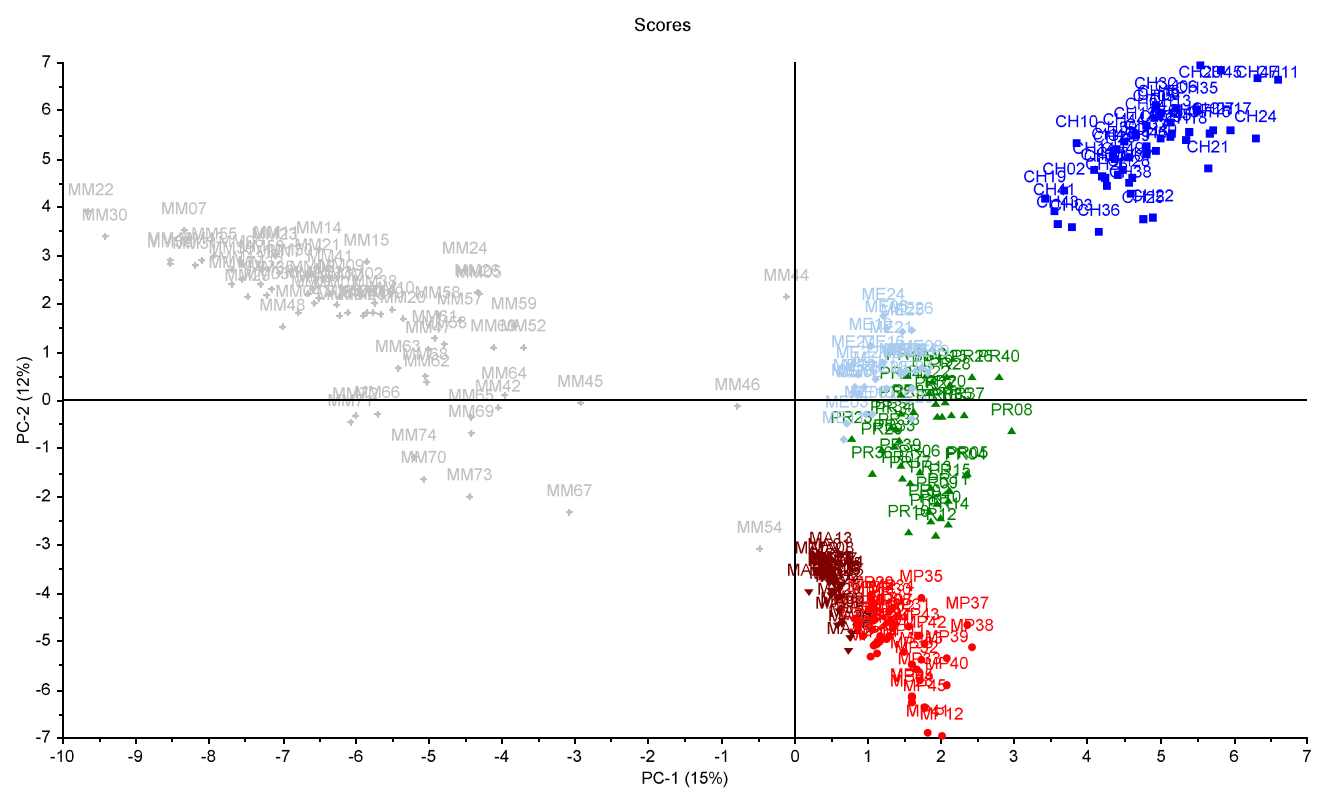

(A) PCA score plot (PC1/PC2) of volatile composition of 269 Corsican honeys

(CH: "chestnut grove" honey; PR: "spring” honey; ME: "summer maquis" honey; MA: "autumn maquis" honey; MP: "spring maquis" honey; MM: honeydew \& blend honey)

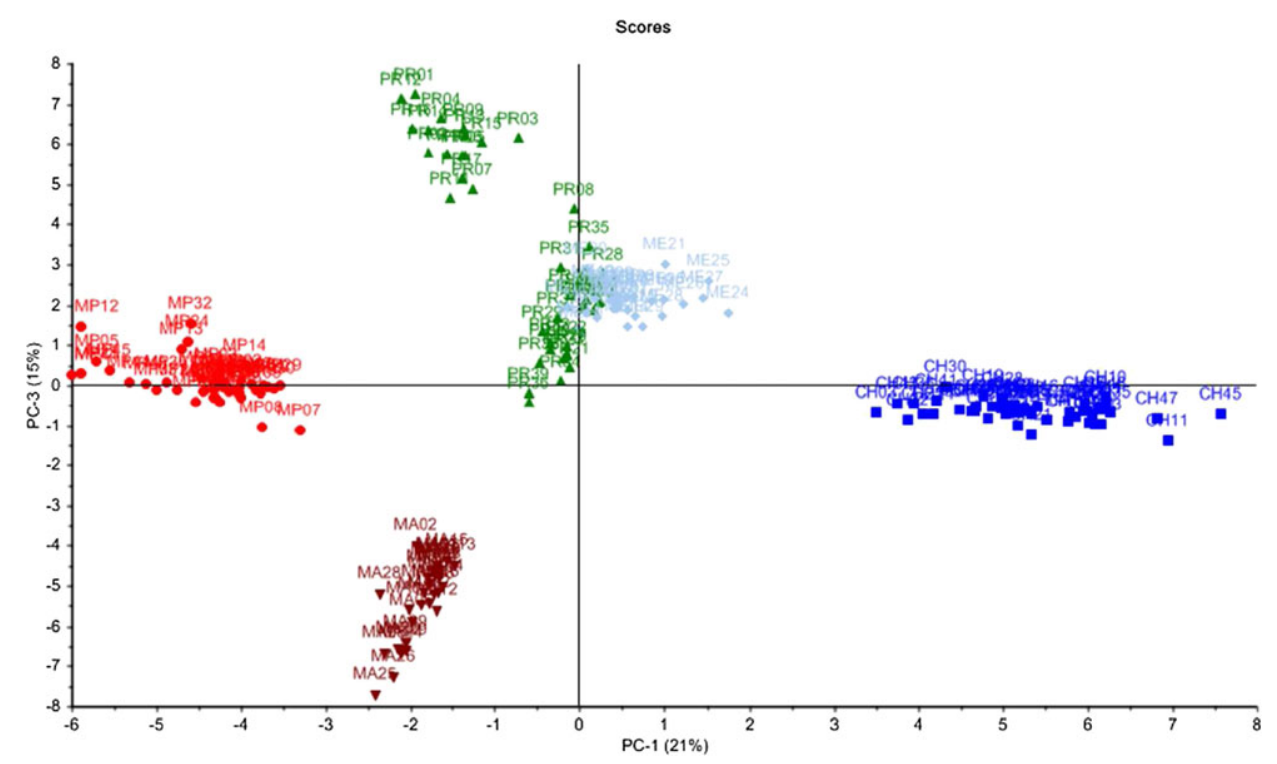

(B) PCA score plot (PC1/PC3) of volatile composition of 195 Corsican blossom honeys

(CH: "chestnut grove" honey; PR: "spring" honey; ME: "summer maquis" honey; MA: "autumn maquis" honey; MP: "spring maquis" honey)

FIGURE 1 A PCA score plot (PC1/PC2) of volatile composition of 269 Corsican honeys. (CH: "chestnut grove" honey; PR: "spring" honey; ME: "summer maquis" honey; MA: "autumn maquis" honey; MP: "spring maquis" honey; MM: honeydew \& blend honey). B PCA score plot (PC1/ PC3) of volatile composition of 195 Corsican blossom honeys $(\mathrm{CH}$ : "chestnut grove" honey; PR: "spring" honey; ME: "summer maquis" honey; MA: "autumn maquis" honey; MP: "spring maquis" honey)

C53 \& C56: 20.8\%) and p-menthen-9-al isomers (C67 \& C68: 3.7\%), while these components were absent (or present at a very low percentage) in other "spring" samples. Another chemical marker of Citrus unifloral honey, ${ }^{11}$ methyl anthranilate $\mathbf{C} 84$, was also detected in volatile fractions of "spring clementine" honeys. This component was not reported in "spring non-clementine" honey compositions, which exhibited high amounts of benzaldehyde C21 (8.9\%) and phenylacetaldehyde C29 (19.9\%) compared with "spring clementine" samples.
The general structure of the dendrogram (Figure 2) produced by Ward's method cluster analysis reinforces the clustering observed by PCA. Indeed, CA performed on volatile data from 195 honey samples allowed us to distinguish the following five groups: "chestnut grove" (CH01-CH50), "spring maquis" (MP01MP45), "autumn maquis" (MA01-MA30) and "spring clementine" (PR01-PR17) honeys, which were separated into distinctive clusters, while the "spring non-clementine" (PR18-PR41) and 
TABLE 2 Statistics of the PLS regression models for the volatile composition of Corsican honeys

\begin{tabular}{llllll} 
Honey ranges & SEC & $\mathrm{R}^{2}$ & $\mathrm{FN}$ & $\mathrm{SEP}$ & $\mathrm{Q}^{2}$ \\
\hline Chestnut grove & 0.073 & 0.96 & 3 & 0.76 & 0.96 \\
Autumn maquis & 0.082 & 0.96 & 3 & 0.085 & 0.97 \\
Summer maquis & 0.079 & 0.96 & 7 & 0.143 & 0.88 \\
Honeydew & 0.101 & 0.97 & 3 & 0.148 & 0.95 \\
Spring maquis & 0.079 & 0.97 & 2 & 0.098 & 0.97 \\
Spring & 0.099 & 0.96 & 5 & 0.142 & 0.92
\end{tabular}

SEC: Standard error of calibration;

$\mathrm{R}^{2}$ : Coefficients correlation in calibration;

SEP: Standard error or prediction;

$\mathrm{Q}^{2}$ : Coefficients correlation in prediction;

FN: Factor number.

"summer maquis" (ME01-ME29) honeys were classed into the same group.

\subsection{Data analysis of honeydew and blend honeys}

Differentiation of Corsican honeydew and blend honeys according to volatile chemical variability is shown in Figure 3. The first and second axes (PC1/PC2) of the PCA represent $43 \%$ of the total spectral variance. The honeydew and blend honeys were separated by PCA into two main groups. The first group (negatively correlated on the PC1 axis) of 50 honey samples, including 43 Metcalfa honeydew (MM01-MM43), two traditional honeydew (MM47 and MM48), and five blend honeys (MM49-MM53), were characterized by higher amounts of 3-furaldehyde (C10: 24.2\%) and linear acids (C77 and C88: $23.6 \%$ ) than samples in the second group (positively correlated on the PC1 axis), which included 20 blend honeys (MM55-MM74, C10: 13.4\%, C77 and C88: 11.1\%). The latter samples showed complex chemical compositions leading to three subgroups according to nectariferous origins: seven honeys (MM55-MM61) exhibited a high content of 2-aminoacetophenone C79 (21.3\%), a chemical marker of C. sativa nectar contribution; seven samples (MM68-MM74) were characterized by high amounts of two specific components of nectariferous E. arborea input, $p$-anisaldehyde C70 (12.5\%) and 4propylanisol C75 (16.1\%); and six samples (MM62-MM67) possessed an intermediate chemical profile between the two previous subgroups with 2-aminoacetophenone $\mathbf{C 7 9}$ (8.2\%) associated with $p$ anisaldehyde C70 (6.6\%) and 4-propylanisol C75 (7.5\%), suggesting combined nectar contributions of $C$. sativa and E. arbora.

Finally, three "traditional honeydew" samples (MM44-MM46) and one blend honey (MM54) exhibited an atypical volatile composition with high content of benzaldehyde (C21: 10.2-14.3\%) associated with

TABLE 3 Classification matrix obtained in prediction (PLS-DA regression) honey origin

\begin{tabular}{llrrrrrrrr} 
Honey ranges & $\begin{array}{l}\text { Number of } \\
\text { latent variables }\end{array}$ & CH & MA & ME & MM & MP & PR & $\begin{array}{l}\text { False negative } \\
\text { samples }\end{array}$ & $\begin{array}{l}\text { False positive } \\
\text { samples }\end{array}$ \\
\hline CH $(n=25)$ & 3 & 25 & 0 & 0 & 0 & 0 & 0 & 0 & 0 \\
MA $(n=22)$ & 3 & 3 & 0 & 22 & 0 & 0 & 0 & 0 & 0 \\
ME $(n=20)$ & 7 & 7 & 0 & 0 & 20 & 0 & 0 & 1 & 0 \\
MM $(n=14)$ & 3 & 3 & 0 & 0 & 0 & 14 & 0 & 0 & 0 \\
MP $(n=14)$ & 2 & 2 & 0 & 0 & 0 & 0 & 14 & 0 & 0 \\
PR $(n=36)$ & 5 & 5 & 0 & 0 & 0 & 0 & 0 & 35 \\
\hline
\end{tabular}

$\mathrm{CH}$ : "chestnut grove" honey; MA: "autumn maquis" honey; ME: "summer maquis" honey; MM: "honeydew maquis"; MP: "spring maquis" honey; PR: "spring" honey

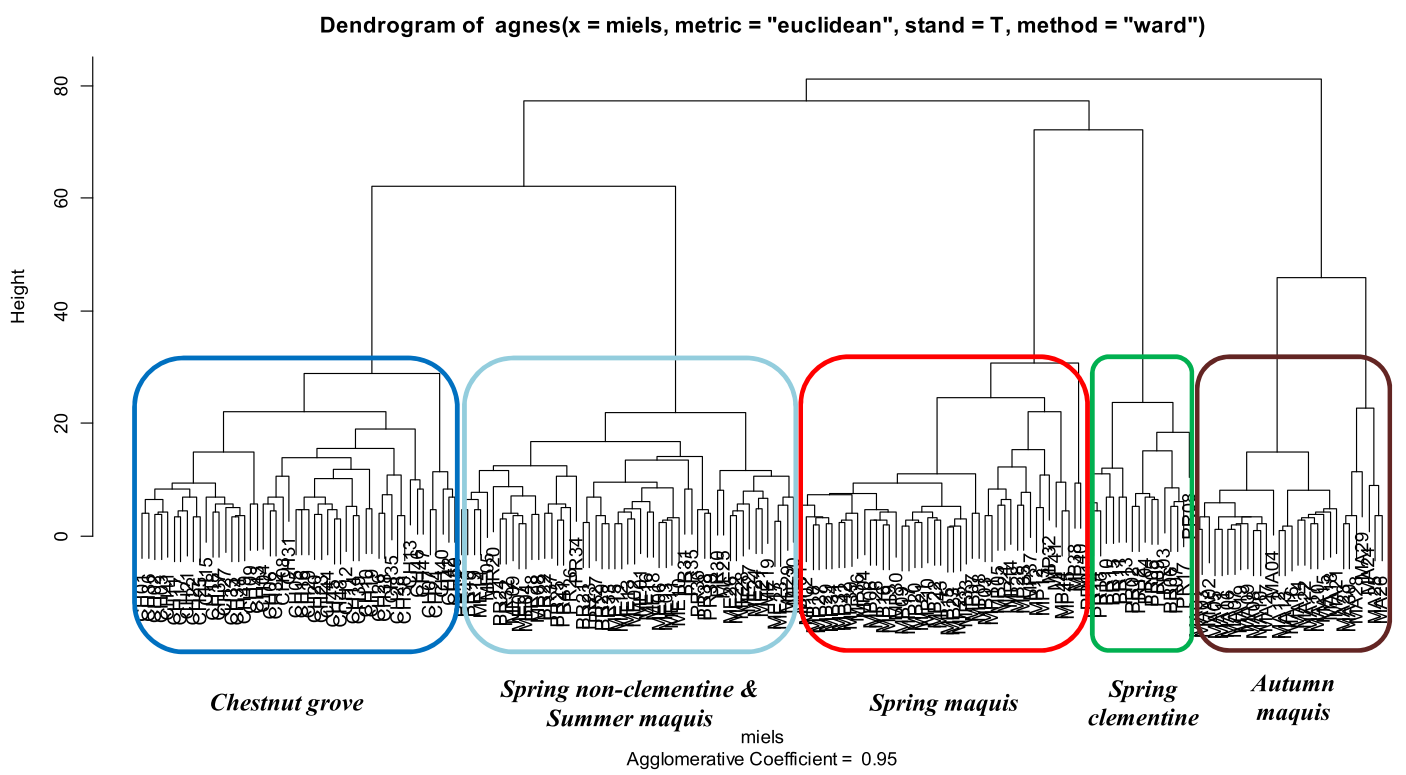

FIGURE 2 Dendrogram of volatile composition of 195 Corsican blossom honeys 


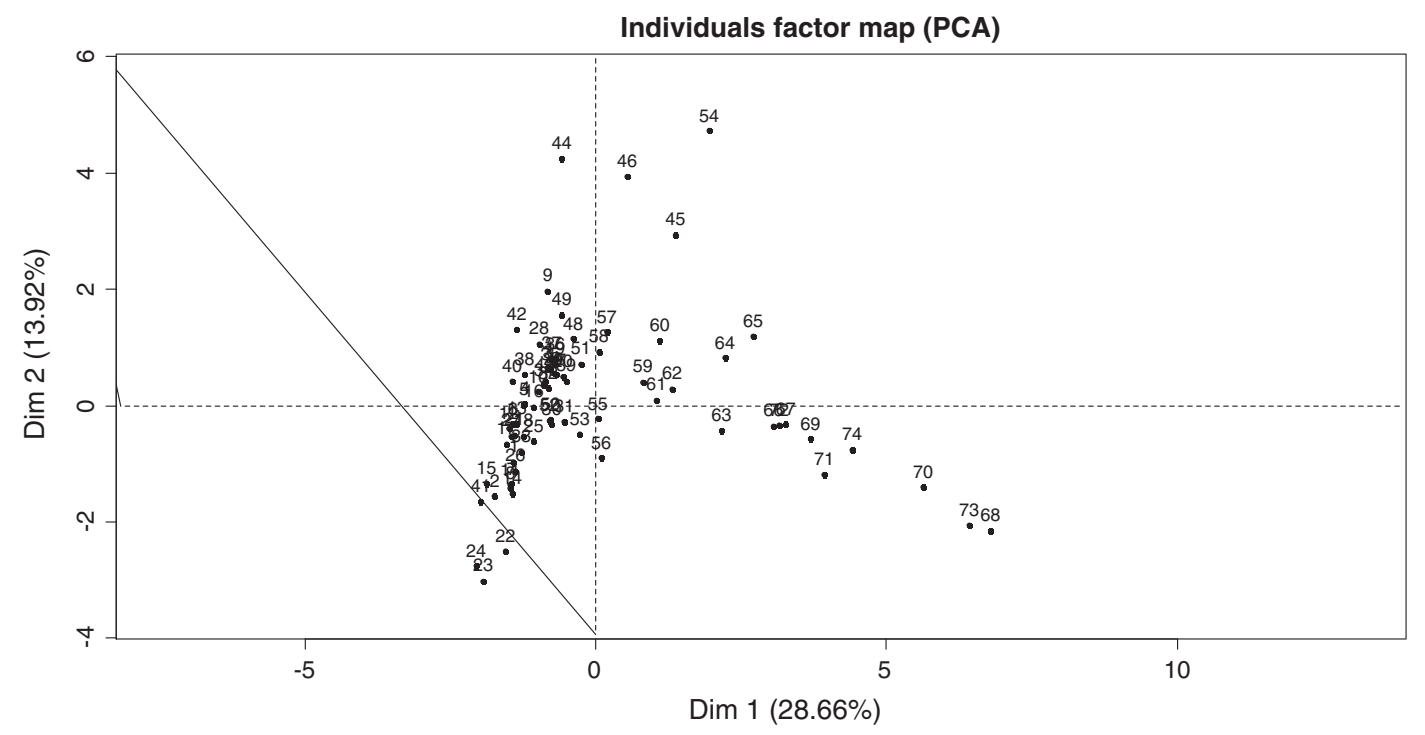

FIGURE 3 PCA score plot (PC1/PC2) of volatile composition of 74 Corsican honeydew and blend honeys (MM01 - MM74)

an abundance of linear aldehydes (62.2\%) for sample MM44 or with a high content of isophorone for samples MM45 and MM46 (C46: 9.4\%, $13.5 \%$, respectively). Finally, MM54 was dominated by isophorone C46 (15.1\%), 2,3,4-trimethylphenol C73 (9.8\%), and 3,4,5trimethylphenol $\mathrm{C} 83$ (38.6\%), which assumes a contribution of $A$. unedo nectar.

\section{4 | CONCLUSIONS}

The volatile fraction of 269 Corsican honeys was characterized by 105 compounds amounting to $60.7-99.7 \%$ of the total composition. This study is the first to report the chemical composition of Corsican honeydew honey, especially Metcalfa honeydew. This approach allowed differentiation of Corsican honeydew honey and blossom honey based on their richness of 3-furaldehyde in the category of "honeydew maquis". For the different blossom honeys, some characteristic compounds were also identified for different botanical origins, including 2-aminoacetophenone ("chestnut grove" honey), $p$-anisaldehyde and 4-n-propylanisole ("spring maquis"), isophorone and 3,4,5trimethylphenol ("autumn maquis"), and isomers of lilac aldehyde and p-menthen-9-al ("spring clementine"). The "spring non-clementine" and "summer maquis" honeys possessed similar volatile compositions with a high content of toluene and phenylacetaldehyde. The volatile classification of Corsican honeys was in accordance with the pollinic and sensorial typologies of honeys obtained using a traditional approach.

These results also showed that chemometric analysis of volatile fraction data is useful for detecting the nectar contributions of plant species in honeys with complex melliferous origins. As shown for the blend samples, the high content of 2-aminoacetophenone (marker of "chestnut grove"), $p$-anisaldehyde (marker of "spring maquis"), isophorone (marker of "autumn maquis" honey) and 3 furaldehyde (marker of "honeydew") indicated the C. sativa, E. arborea, $A$. unedo nectar and honeydew contributions, respectively. The results of this study are expected to contribute to the development of an innovative approach using statistical analysis of volatile fractions, thereby allowing researchers to obtain discriminant chemical markers to determine the botanical origins of honeys. In addition, PCA analysis and PLS-DA regression could be effective for identifying class and/or predicting Corsican honeys' botanical origins in new production through comparisons with the database established in this study.

\section{CONFLICT OF INTEREST}

The authors declare no conflict of interest.

\section{ACKNOWLEDGEMENTS}

The authors are indebted to the Délégation Régionale à la Recherche et à la Technologie de Corse (DRRT), the Collectivité Territoriale de Corse (CTC) and European Community for partial financial support.

\section{ORCID}

Julien Paolini (1D http://orcid.org/0000-0002-3109-1430

\section{REFERENCES}

1. Decree $n^{\circ} 2013-1057$ (2013). Décret n²013-1057 du 22 novembre 2013 relatif à l'appellation d'origine contrôlée 'Miel de Corse - Mele di Corsica ! http://www.legifrance.gouv.fr/affichTexte.do?cidTexte= JORFTEXT000028225091 Accessed 16 June 2020.

2. Battesti MJ, Gamisans J, Piana L, Définition du périmètre de productionRapport des experts en vue de la mise à l'enquête. Demande de reconnaissance en A.O.C. 'Miel de Corse - Mele di Corsica'. Institut National des Appelations d'Origine (INAO), Corte, 1997.

3. Battesti M. J., Boulay A. F., Nafteux C., Rapport d'activités 2006 - 2ème partie : conseil scientifique et technique, expertise réalisée dans le cadre du programme d'activité déposé par le syndicat AOC 'Miel de Corse - Mele di Corsica'. Association 'Miel et Pollen', Corte, 2007.

4. Battesti MJ, Contribution à la melissopalynologie méditerranéenne: les miels Corses. PhD Thesis, University of Marseille St. Jérôme (Aix-Marseille III), France, 1990.

5. Battesti MJ, Goeury C. Efficacité de l'analyse mélitopalynologique quantitative pour la certification des origines géographique et 
botanique des miels: le modèle des miels corses. Rev. Palaeobot. Palyno. 1992;75:77-102.

6. Von Der Ohe W, Persano Oddo L, Piana ML, Morlot M, Martin P. Harmonized methods of melissopalynology. Apidologie. 2004;35:18-23.

7. Anklam E. A review of the analytical methods to determine the geographical and botanical origin of honey. Food Chem. 1998;63: 549-562.

8. Pyrzynska K, Biesaga M. Analysis of phenolic acids and flavonoids in honey. Trends in Anal. Chem. 2009;28:893-902.

9. Kaskoniené V, Venskutonis PR. Floral markers in honey of various botanical and geographic origins: a review. Compr. Rev. Food Sci. Food Saf. 2010;9:620-634.

10. Bogdanov S, Ruoff K, Persano Oddo L. Physico-chemical methods for the characterization of unifloral honeys: a review. Apidologie. 2004;35:S4-S17.

11. Cuevas-Glory LF, Pino JA, Santiago LS, Sauri-Duch E. A review of volatile analytical methods for determining the botanical origin of honey. Food Chem. 2007;103:1032-1043.

12. Bianchi F, Careri M, Musci M. Volatile norisoprenoids as markers of botanical origin of Sardinian strawberry-tree (Arbutus unedo L.) honey: characterization of aroma compounds by dynamic headspace extraction and gas chromatography-mass spectrometry. Food Chem. 2005;89:527-532.

13. Jerković I, Tuberoso CIG, Kasum A, Marijanović Z. Volatile Composition of Asphodelus microcarpus Salzm. et Viv. honey obtained by HS-SPME and USE analysed by GC-MS. Chem. Biodiv. 2011;8:587-598.

14. Castro-Vazquez L, Diaz-Maroto MC, Pérez-Coello MS. Volatile composition and contribution to the aroma of Spanish honeydew honeys. Identification of a new chemical marker. J. Agr. Food Chem. 2006;54:4809-4813.

15. Soria AC, Sanz J, Martínez-Castro I. SPME followed by GC-MS: a powerful technique for qualitative analysis of honey volatiles. Eur. Food Res. Technol. 2009;228:579-590.

16. Plutowska B, Chmiel T, Dymerski T, Wardencki W. A headspace solidphase microextraction method development and its application in the determination of volatiles in honeys by gas chromatography. Food Chem. 2011;126:1288-1298.

17. Soria AC, Gonzalez M, De Lorenzo C, Martinez-Castro I, Sanz J. Characterization of artisanal honeys from Madrid (Central Spain) on the basis of their melissopalynological, physicochemical and volatile composition data. Food Chem. 2004;85:121-130.

18. Cajka T, Hajslova J, Pudil F, Riddellova K. Traceability of honey origin based on volatiles pattern processing by artificial neutral networks. J. Chromatogr. A. 2009;1216:1458-1462.

19. Stanimirova I, Üstün B, Cajka T, et al. Tracing the geographical origin of honeys based on volatile compounds profiles assessment using pattern recognition techniques. Food Chem. 2010;118:171-176.

20. Yang Y, Battesti MJ, Djabou N, et al. Melissopalynological origin determination and volatile composition analysis of Corsican "chestnut grove" honeys. Food Chem. 2012;132:2144-2154.

21. Yang Y, Battesti MJ, Paolini J, Muselli A, Tomi P, Costa J. Melissopalynological and volatile composition investigation of Corsican "Erica arborea spring maquis" honeys. Food Chem. 2012;134:37-47.
22. Yang Y, Battesti MJ, Costa J, Paolini J. Characterization of botanical and geographical origin of Corsican "spring" honeys by melisspalynological and volatile analysis. Foods. 2014;3:128-148.

23. Yang Y, Battesti MJ, Costa J, Paolini J. Pollen diversity and volatile variability of honey from Corsican Anthyllis hermanniae L. habitat. Chem. \& Biodiv. 2014;11:1900-1913.

24. Yang Y, Battesti MJ, Costa J, Paolini J. Melissopalynological and volatile analysis of honeys from Corsican Arbutus unedo L. habitat. Nat. Prod. Commun. 2014;9:1523-1526.

25. Gonnet M, Vache G. Le goût du miel. Paris: U.N.A.F.; 1985.

26. Konig WA, Hochmuth DH, Joulain D, Terpenoids and Related Constituents of Essential oils. Library of Mass Finder 2.1, Institute of Organic Chemistry, Hamburg, 2001.

27. Lafhal S, Vanloot P, Bombarda I, Kister J, Dupuy N. Raman spectroscopy for identification and quantification analysis of essential oil varieties: a multivariate approach applied to lavender and lavandin essential oils. J. Raman Spectrosc. 2015;46:577-585.

28. Kemsley K. Discriminant analysis of high-dimensional data: A comparison of principal components analysis and partial least squares data methods. Chemometr. Intell. Lab. 1996;33:47-61.

29. Vandeginste GM, Massart DL, Buydens LMC, De Jung S, Lewi PJ, Smeyers-Verbeke J. Handbook of Chemometrics, Part B. Amsterdam: Elsevier; 1998.

30. Roussel S, Bellon-Maurel V, Roger JM, Grenier P. Authenticating white grape must variety with classification models based on aroma sensors, FT-IR and UV spectrometry. J. Food Eng. 2003;60:407-419.

31. Ciosek P, Brzozka Z, Woblewski W, Martinelli E, Di Natalec C, D'Amico A. Direct and two-stage data analysis procedures based on PCA, PLS-DA and ANN for ISE-based electronic tongue - Effect of supervised feature extraction. Talanta. 2005;67:590-596.

32. Verzera A, Condurso C. Sampling techniques for the determination of the volatile fraction of honey. Reference Module in Chemistry, Molecular Sciences and Chemical Engineering in Comprehensive Sampling and Sample Preparation. 2012;4:87-117.

33. Guyot C, Bouseta A, Scheirman V, Collin S. Floral origin markers of chestnut and lime tree honeys. J. Agr. Food Chem. 1998;46:625-633.

34. Jerković I, Mastelić J, Marijanović Z, Klein Z, Jelić M. Comparison of hydrodistillation and ultrasonic solvent extraction for the isolation of volatile compounds from two unifloral honeys of Robinia pseudoacacia L. and Castanea sativa L. Ultrason. Sonochem. 2007;14:750-756.

35. Guyot C, Scheirman V, Collin S. Floral origin markers of heather honeys: Calluna vulgaris and Erica arborea. Food Chem. 1999;64:3-11.

36. Dalla Serra A, Franco MA, Mattivi F, Ramponi M, Vacca V, Versini G. Aroma characterization of Sardinian strawberry tree (Arbutus unedo L.) honey. Ital. J. Food Sci. 1999;11:47-56. 